\title{
Hybrid AIN-SiC deep ultraviolet Schottky barrier photodetectors
}

\author{
R. Dahal, T. M. Al Tahtamouni, Z. Y. Fan, J. Y. Lin, ${ }^{\text {a) }}$ and H. X. Jiang ${ }^{\text {b) }}$ \\ Department of Physics, Kansas State University, Manhattan, Kansas 66506-2601
}

(Received 1 April 2007; accepted 3 June 2007; published online 26 June 2007)

\begin{abstract}
Deep ultraviolet (DUV) Schottky barrier photodetectors have been demonstrated by exploiting the epitaxial growth of high quality AlN epilayer on $n$-type $\mathrm{SiC}$ substrate. The fabricated AlN $/ n$-SiC hybrid Schottky barrier detectors exhibited a peak responsivity at $200 \mathrm{~nm}$ with very sharp cutoff wavelength at $210 \mathrm{~nm}$, very high reverse breakdown voltages $(>200 \mathrm{~V})$, very low dark currents (about $10 \mathrm{fA}$ at a reverse bias of $50 \mathrm{~V}$ ), and high responsivity and DUV to UV/visible rejection ratio. These outstanding features are direct attributes of the fundamental material properties and high quality of AlN epilayers. The fabricated photodetectors also have a thermal energy limited detectivity at zero bias of about $1.0 \times 10^{15} \mathrm{~cm} \mathrm{~Hz}^{1 / 2} \mathrm{~W}^{-1}$. These results demonstrated that AlN epilayers are an excellent candidate as an active material for DUV optoelectronic device applications. (C) 2007 American Institute of Physics. [DOI: 10.1063/1.2752126]
\end{abstract}

Aluminum nitride (AlN) has emerged as a very important material due to recent advances in high quality material growth. ${ }^{1-3}$ Light emitting diodes with emission wavelength of $210 \mathrm{~nm}$ have been demonstrated using pure AlN. ${ }^{4}$ Furthermore, we have recently demonstrated $200 \mathrm{~nm}$ metalsemiconductor-metal (MSM) deep ultraviolet (DUV) photodetectors based on pure AlN. ${ }^{5}$ DUV photodetectors have a wide range of applications including secure space communication, missile threat detection, UV radiation monitoring in environment, and biological agent detection. As a consequence of its widest direct band gap $(6.1 \mathrm{eV})$ among III-nitride semiconductors, combined with its outstanding electro-optical and physical properties, AlN also appears to be very promising for the development of vacuum UV and extreme UV detectors where Si-based photodetectors have reached their limits.

To date, AlGaN based Schottky, $p-i-n$, and MSM photodetectors grown both on $\mathrm{SiC}$ and sapphire substrates with excellent performances have been reported. ${ }^{6-18}$ In contrast to Al-rich AlGaN based $p-i$ - $n$ photodetectors, AlGaN Schottky barrier detectors are majority carrier devices, which do not face the challenging requirement of high quality $p$-type AlGaN layer for low resistance Ohmic contact formation. Furthermore, the ease of growth, fabrication, efficient photogenerated carriers collection near the semiconductor surface, and high responsivity at zero bias are the other advantages of Schottky barrier photodetectors. The shortest cutoff wavelength of $\mathrm{Al}_{x} \mathrm{Ga}_{1-x} \mathrm{~N}$-based Schottky barrier photodetectors achieved so far is $265 \mathrm{~nm}$, corresponding to an $\mathrm{Al}$ mole fraction $x \sim 0.5$. $^{18}$ AlGaN-based Schottky barrier photodetectors grown on $\mathrm{SiC}$ substrates for $\mathrm{Al}$ mole fraction of $\sim 0.4$ were shown to possess a zero bias detectivity of $7.9 \times 10^{14} \mathrm{~cm} \mathrm{~Hz}^{1 / 2} \mathrm{~W}^{-1}$ and dark current density of $2.2 \times 10^{-10} \mathrm{~A} \mathrm{~cm}^{-2}$ at $-5 \mathrm{~V}^{19}$

The growth of high quality AlN epilayer directly on highly conductive $\mathrm{SiC}$ substrates naturally provides a hybrid Schottky barrier photodetector structure that does not require the growth of $n$-type Ohmic contact layer. AlN layer has outstanding interfacial properties when deposited on $\mathrm{SiC}$ due

\footnotetext{
${ }^{\text {a) }}$ Electronic mail: jylin@phys.ksu.edu

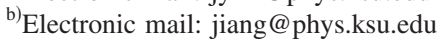

to an excellent lattice match to $\mathrm{SiC}(1 \%) .^{20-23}$ Compared to $\mathrm{AlGaN} / n$-AlGaN Schottky barrier photodetector structures grown on sapphire substrates, AlGaN/n-SiC hybrid Schottky barrier photodetector structures are expected to possess higher crystalline quality (and hence lower dislocation density) and minimal doping induced defects. On the other hand, compared to photodetectors based on pure indirect band gap $\mathrm{SiC}, \mathrm{AlGaN} / n-\mathrm{SiC}$ hybrid Schottky barrier photodetector structures are expected to provide higher detectivity and variable cutoff wavelength due to their adjustable direct band gaps. We report here on the growth, fabrication, and characterization of $\mathrm{AlN} / n-\mathrm{SiC}$ hybrid Schottky barrier photodetectors. The fabricated photodetectors exhibit very high reverse breakdown voltages, extremely low dark currents, high responsivity, high DUV to UV/visible rejection ratio, and high thermal energy limited detectivity at zero bias.

Undoped AlN epilayers of about $1 \mu \mathrm{m}$ thickness were grown on heavily doped $n$-type $\mathrm{Si}$-face $4 H$-SiC substrates by metal organic chemical vapor deposition. Trimethylaluminum and ammonia $\left(\mathrm{NH}_{3}\right)$ were the sources for $\mathrm{Al}$ and $\mathrm{N}$, respectively. Atomic force microscopy revealed a very smooth surface morphology of AlN epilayer with a rootmean-square value of about $0.6 \mathrm{~nm}$. The device fabrication process consisted of the following steps. Ohmic contact was formed on the $\mathrm{SiC}$ substrate side by e-beam evaporation of $150 \mathrm{~nm} \mathrm{Ni}$ and $50 \mathrm{~nm} \mathrm{Au}$, followed by a rapid thermal annealing at $950{ }^{\circ} \mathrm{C}$ for $60 \mathrm{~s}$. Before annealing, $100 \mathrm{~nm} \mathrm{SiO}$ was deposited on AIN epilayer by plasma enhanced chemical vapor deposition (PECVD) for protection of AlN epilayer during high temperature annealing, which was later removed by wet etching. Photolithography was used to define the semitransparent Schottky contact area. A $10 \mathrm{~nm}$ Pt was deposited by e-beam evaporation to form Schottky contacts. Then $100 \mathrm{~nm} \mathrm{SiO}_{2}$ was deposited by PECVD for passivation. Photolithography and selective area wet etching of $\mathrm{SiO}_{2}$ were used to open window for Schottky contact pad deposition. A Ni (40 nm)/ Au (160 nm) bilayer were deposited using e-beam evaporation to form Schottky bonding pad. Finally, devices were bonded in ten pin flat packs for characterization. Our measurement system consisted of deuterium light source, monochromator, Keithley 2400 source 


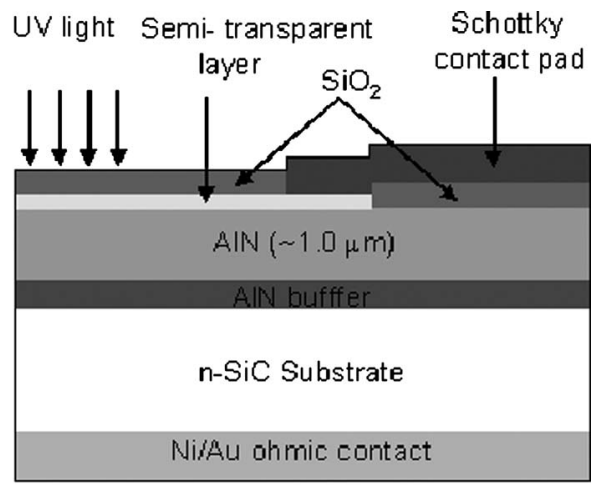

(a)

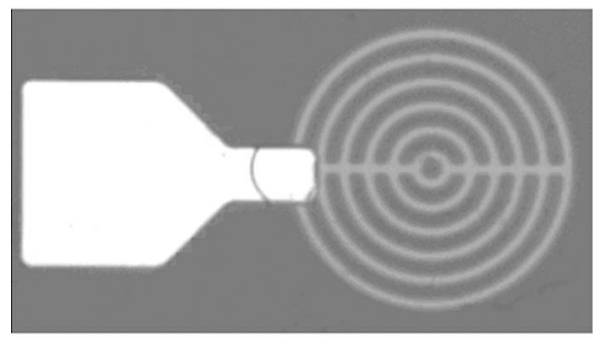

(b)

FIG. 1. (a) Schematic layer structure of AlN $/ n$-SiC hybrid Schottky barrier photodetector and (b) optical microscopy image of a fabricated photodetector with a device size of $100 \mu \mathrm{m}$ in diameter.

meter, and 617 electrometer for spectral response and $I-V$ characteristic measurements.

Figure 1(a) shows the schematic layer structure of the fabricated photodetectors employed in this study, in which undoped AIN epilayer serves as an active layer. Figure 1(b) shows the optical microscopy image of a fabricated device. The size of top Schottky contact is $100 \mu \mathrm{m}$ in diameter $(d=100 \mu \mathrm{m})$. Figure 2 shows the typical dark currentvoltage $(I-V)$ characteristics of the device. The fabricated device showed a reverse breakdown voltage $\left(V_{B}\right)$ exceeding $200 \mathrm{~V}$, which corresponds to a breakdown field exceeding $2.2 \times 10^{6} \mathrm{~V} / \mathrm{cm}$. These devices also exhibit very low dark currents $\left(I_{d}\right)$, which is below $10 \mathrm{fA}$ at a reverse bias voltage $\left(V_{b}\right)$ of $-50 \mathrm{~V} . I_{d}$ is in picoampere range at $V_{b}=-200 \mathrm{~V}$.

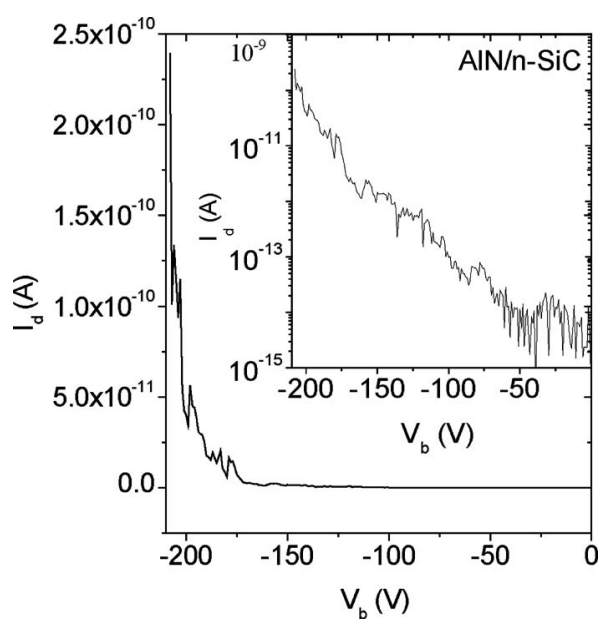

FIG. 2. $I-V$ characteristics of an AlN/n-SiC hybrid Schottky barrier photodetector. The inset shows the same plot in semilog scale. Therefore, the thermal energy limited specific detectivity is
Downloaded 12 Jul 2010 to 129.118 .86 .45 . Redistribution subject to AlP license or copyright; see http://apl.aip.org/apl/copyright.jsp

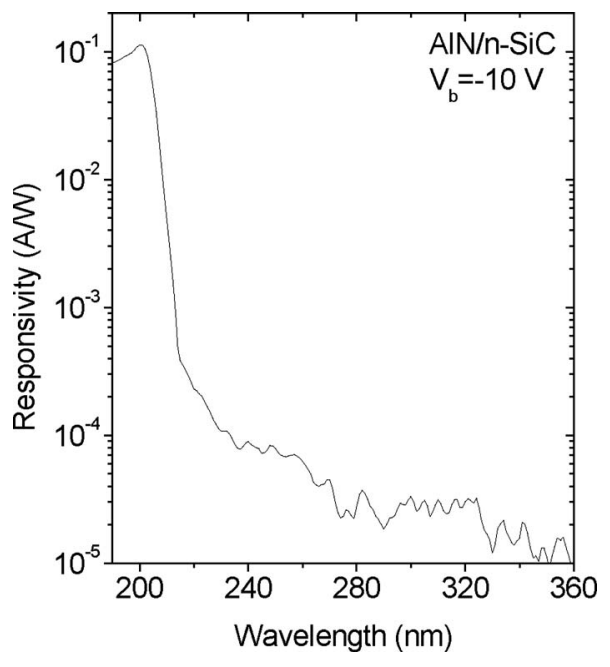

FIG. 3. Spectral photoresponse of an AlN/n-SiC hybrid Schottky barrier photodetector measure at $V_{b}=-10 \mathrm{~V}$.

Beyond $-200 \mathrm{~V}, I_{d}$ starts to increase rapidly. The differential resistance $R(=d V / d I)$ in the range of $V_{b}$ between 0 and $-50 \mathrm{~V}$ was in excess of $5 \times 10^{16} \Omega$. These features are the direct attributes of the outstanding material properties of high quality AlN epilayers including large energy band gap and dielectric constant.

Spectral photoresponse measurements have been carried out for $d=100 \mu \mathrm{m}$ devices at different bias voltages. Figure 3 shows the spectral photoresponse in the wavelength range from 190 to $360 \mathrm{~nm}$ measured under $V_{b}=-10 \mathrm{~V}$. These AlNbased Schottky photodetectors have peak responsivity of about $0.12 \mathrm{~A} / \mathrm{W}$ at $200 \mathrm{~nm}$ and very sharp cutoff around $210 \mathrm{~nm}$. This is the shortest cutoff wavelength and highest breakdown voltage attained so far for AlGaN based Schottky barrier photodetectors. These cutoff wavelength and peak response wavelength are comparable to those of AlN based MSM photodetectors we previously reported. ${ }^{5}$ Also, a DUV to near UV rejection ratio of more than four orders of magnitude has been observed. Furthermore, we did not observe photoresponses from $\mathrm{SiC}$ substrate. This can be attributed to the large conduction- and valance-band offsets at the $\mathrm{AlN} / \mathrm{SiC}$ interface, which were estimated to be around 1.3 and $1.7 \mathrm{eV}$, respectively. ${ }^{23}$ The large band offsets, in general, will prevent the collection of photoexcited carriers in the lower band gap contact layer, ${ }^{17}$ which is $n$-SiC in this case.

The bias $\left(V_{b}\right)$ dependent spectral responsivity has also been studied. In Fig. 4, we plot the spectral photoresponses measured in the bias range from 0 to $-25 \mathrm{~V}$. The peak responsivity at $\lambda=200 \mathrm{~nm}$ as a function of $V_{b}$ is shown in the inset of Fig. 4. The responsivity initially increases by a factor of 1.4 when $V_{b}$ changes from 0 to $-5 \mathrm{~V}$ and it then increases slightly by a factor of only 1.2 when $V_{b}$ increases from -5 to $-25 \mathrm{~V}$. Such a weak $V_{b}$ dependent responsivity observed in the bias range of -5 to $-25 \mathrm{~V}$ seems to indicate that the $1 \mu \mathrm{m}$ thick undoped AlN active layer was almost fully depleted up to $V_{b}=-5 \mathrm{~V}$. The device also exhibits a relative high responsivity of $0.078 \mathrm{~A} / \mathrm{W}$ at $200 \mathrm{~nm}$ in the photovoltaic mode (zero bias).

For solar blind photodetectors based on wide band gap semiconductors, the detectivity performance is thermally limited because the noise current due to background radiation is far less than the noise current due to thermal energy. 


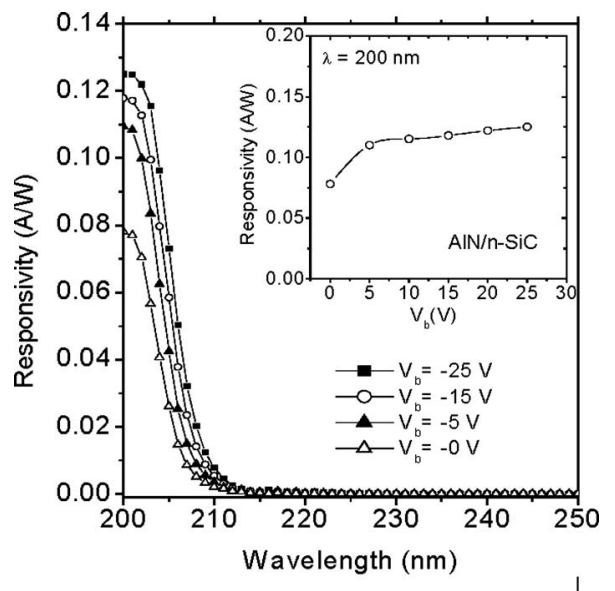

FIG. 4. Spectral photoresponses of an AlN $/ n$-SiC hybrid Schottky barrier photodetector measure at different bias voltages $V_{b}$. The inset shows the peak responsivity at $200 \mathrm{~nm}$ as a function of $V_{b}$. The responsivity in the photovoltaic mode (zero bias) is $0.078 \mathrm{~A} / \mathrm{W}$.

given by $D=R_{\lambda}\left(R_{0} A / 4 k T\right)^{1 / 2}$, where $R_{\lambda}$ is the zero bias responsivity, $R_{0}$ is differential resistance, $k$ is Boltzmann's constant, $A$ is the detector active area, and $T$ is the absolute temperature. $^{24}$ With resistance-area product $R_{0} A=3.93$ $\times 10^{12} \Omega \mathrm{cm}^{2}$, the room temperature specific detectivity of our AlN $/ n-\mathrm{SiC}$ hybrid Schottky barrier photodetectors is deduced to be about $1.0 \times 10^{15} \mathrm{~cm} \mathrm{~Hz}^{1 / 2} \mathrm{~W}^{-1}$, which is one of the highest values reported so far for AlGaN UV photodetectors. This very high detectivity is due to the extremely low leakage current and high zero bias responsivity.

The very high breakdown electric field and extremely low dark current over a wide range of applied reverse bias obtained for these AlN/n-SiC hybrid Schottky photodetectors suggest that it is feasible to build avalanche photodetector structures on $\mathrm{AlN} / n-\mathrm{SiC}$ templates by further improving material quality and device design, primarily through further reduction of the dislocation density, and optimizing device area and active layer thickness.

In summary, we report on the growth, fabrication, and characterization of AlN $/ n$-SiC hybrid Schottky photodetectors and demonstrated the potential advantages of AlN as an active material for DUV optoelectronic device applications. These photodetectors exhibit very high reverse breakdown voltage $(>200 \mathrm{~V})$, extremely low dark current (less than
$10 \mathrm{fA}$ at a reverse bias of $-50 \mathrm{~V}$ ), high responsivity, high thermal energy limited detectivity, and high DUV to UV/ visible rejection ratio.

This work is supported by DARPA and monitored by Henryk Temkin.

${ }^{1}$ J. Li, K. B. Nam, M. L. Nakarmi, J. Y. Lin, and H. X. Jiang, Appl. Phys. Lett. 81, 3365 (2002).

${ }^{2}$ K. B. Nam, J. Li, M. L. Nakarmi, J. Y. Lin, and H. X. Jiang, Appl. Phys. Lett. 81, 3365 (2002).

${ }^{3}$ J. Li, K. B. Nam, M. L. Nakarmi, J. Y. Lin, H. X. Jiang, P. Carrier, and S. H. Wei, Appl. Phys. Lett. 83, 5163 (2003).

${ }^{4}$ Y. Taniyasu, M. Kasu, and T. Makomoto, Nature (London) 441, 325 (2006).

${ }^{5}$ J. Li, Z. Y. Fan, R. Dahal, M. L. Nakarmi, J. Y. Lin, and H. X. Jiang, Appl. Phys. Lett. 89, 213510 (2006).

${ }^{6}$ B. W. Lim, Q. C. Chen, J. Y. Yang, and M. Asif Khan, Appl. Phys. Lett. 68, 3761 (1996).

${ }^{7}$ A. Osinsky, S. Gangopadhyay, B. W. Lim, M. Z. Anwar, M. A. Khan, D. V. Kuksenkov, and H. Temkin, Appl. Phys. Lett. 72, 742 (1998).

${ }^{8}$ C. J. Collins, U. Chowdhury, M. M. Wong, B. Yang, A. L. Beck, R. D. Dupuis, and J. C. Campbell, Appl. Phys. Lett. 80, 3754 (2002).

${ }^{9}$ U. Chowdhury, M. M. Wong, C. J. Collins, B. Yang, J. C. Denyszyn, J. C. Campbell, and R. D. Dupuis, J. Cryst. Growth 248, 552 (2003).

${ }^{10}$ S. Butun, T. Tut, B. Butan, M. Gokkavas, H. Yu, and E. Ozbay, Appl. Phys. Lett. 88, 123503 (2006).

${ }^{11}$ C. Pernot, A. Hirano, M. Iwaya, T. Detchprohm, H. Amano, and I. Akasaki, Jpn. J. Appl. Phys., Part 1 39, 387 (2000).

${ }^{12}$ N. Biyikli, O. Aytur, I. Kimukin, T. Tut, and E. Ozbay, Appl. Phys. Lett. 81, 3272 (2002).

${ }^{13}$ N. Biyikli, I. Kimukin, O. Aytur, and E. Ozbay, IEEE Photonics Technol. Lett. 16, 1718 (2004).

${ }^{14}$ T. Tut, N. Biyikli, I. Kimukin, T. Kartaloglu, O. Aytur, M. S. Unlc, and E. Ozbay, Solid-State Electron. 49, 117 (2005).

${ }^{15}$ X. Xin, F. Fan, T. W. Koeth, C. Joseph, J. Hu, and J. H. Zhao, Electron. Lett. 41, 1192 (2005).

${ }^{16}$ A. Sciuto, F. Roccaforte, S. D. Franco, and Vito Raineri, Appl. Phys. Lett. 89, 081111 (2006).

${ }^{17}$ E. J. Tarsa, P. Kozodoy, J. Ibbetson, B. P. Keller, G. Parish, and U. Mishra, Appl. Phys. Lett. 77, 316 (2000).

${ }^{18}$ H. Miyaki, H. Yasukawa, Y. Shibata, A. Motogaito, K. Hiramatsu, Y. Ohuchi, Y. Hamamura, and K. Fukui, Phys. Status Solidi A 200, 151 (2003).

${ }^{19}$ H. Jiang, T. Egawa, and H. Ishikawa, IEEE Photonics Technol. Lett. 18, 1353 (2006).

${ }^{20}$ M. O. Aboelfotoh, R. S. Kern, S. Tanaka, and R. F. Davis, Appl. Phys. Lett. 69, 2873 (1996).

${ }^{21}$ C. M. Zetterling, M. Östling, N. Nordell, O. Schön, and M. Deschler, Appl. Phys. Lett. 70, 3549 (1997).

${ }^{22}$ L. Lipkin and J. Palmour, IEEE Trans. Electron Devices 46, 525 (1999).

${ }^{23}$ J. Choi, R. Puthenkovilakam, and G. P. Chang, Appl. Phys. Lett. 86, 192101 (2005).

${ }^{24}$ S. Donati, Photodetectors, Devices, Circuits, and Applications (PrienticeHall, Englewood Cliffs, NJ, 2000), p. 43. 